\title{
Characterization of Volatile Compounds from the Concrete of Jasminum grandiflorum Flowers
}

\author{
P. Ranchana*, M. Ganga, M. Jawaharlal and M. Kannan \\ Department of Floriculture and Landscaping, HC\& RI, TNAU, Coimbatore- 3, \\ Tamil Nadu, India \\ *Corresponding author
}

\begin{tabular}{|c|c|}
\hline & A B S T RA C T \\
\hline & $\begin{array}{l}\text { Jasmine oil has great value for treating severe depression, respiratory tract, for } \\
\text { muscle pain and for toning the skin. Three species of jasmine viz., Jasminum }\end{array}$ \\
\hline Keywords & $\begin{array}{l}\text { sambac, Jasminum auriculatum and Jasminum grandiflorum is cultivated in a } \\
\text { commercial scale (Rimando, 2003; Green and Miller, 2009). Among these, the }\end{array}$ \\
\hline $\begin{array}{l}\text { Jasmine, } \\
\text { Jasminum } \\
\text { grandiflorum, } \\
\text { Genotypes, } \\
\text { Concrete, GC-MS }\end{array}$ & $\begin{array}{l}\text { flowers of Jasminum grandiflorum are white with faint, delightfully fragment, and } \\
\text { borne in lax, terminal inflorescences. In this study, Jasminum grandiflorum } \\
\text { concrete extraction was carried out by solvent extraction with hexane for three } \\
\text { genotypes viz., CO- } 1 \text { pitchi, CO-2 pitchi and White pitchi which is cultivated in }\end{array}$ \\
\hline Article Info & chromatography- mass spectrometry (GC-MS). The results showed that \\
\hline $\begin{array}{l}\text { Accepted: } \\
\text { 21 June } 2017\end{array}$ & $\begin{array}{l}\text { percentage yield of concrete were in the range of } 0.29 \text { to } 0.34 \% \text { per cent. The } \\
\text { major chemical components detected were Pentane, } 3 \text {-ethyl-2, 2, 2-dimethyl-; } 1 \text { - }\end{array}$ \\
\hline $\begin{array}{l}\text { Available Online: } \\
10 \text { July } 2017\end{array}$ & Pentanol; 4-methyl-2-propyl-; Triacontane; Nonacosane; Octacosane; \\
\hline & $\begin{array}{l}\text { study is selective, rapid and efficient for the identification of volatile components } \\
\text { and composition variations. }\end{array}$ \\
\hline
\end{tabular}

\section{Introduction}

Jasmine is one of the most popular and important traditional loose flowers grown in India. Three species of jasmine viz., Jasminum sambac, Jasminum auriculatum and Jasminum grandiflorum is cultivated in a commercial scale (Rimando, 2003; Green and Miller, 2009). It holds a vital place in all the religious, social and cultural activities of the Indian society. Jasmine flowers have multifarious uses including use as fresh flowers for garland making for adorning hair of women and in religious offerings and also for extraction of its highly valued essential oil which is popularly used in the perfumery industry.

Among these, Jasminum grandiflorum is semi-evergreen to deciduous shrub reaching a length of 8 meters, often with pendulous branches (Kulkarmi and Ansari, 2004; Sharma et al., 2005).

Jasmine oil has great value for treating severe depression, respiratory tract, for muscle pain 
and for toning the skin. This oil is expensive. It takes approximately 10000 flowers to make 1 kilo of concrete jasmine. Egypt is the main producer of jasmine oil.

The fully blossomed flower is used to extract its oil and concrete. A non-polar solvent such as Hexane is used to "wash" the aromatic compounds out of the flowers. After the hexane is evaporated a waxy, semisolid substance known as a "concrete" is left. The concrete then undergoes a series of "washings" with a polar solvent such as ethanol. The polarity of the ethanol will allow extraction of the volatile aromatics from the concrete while leaving behind the non-polar plant waxes which do not dissolved in the ethanol. Finally, the ethanol is evaporated to leave behind the ABSOLUTE which will typically have $1-5 \%$ ethanol remaining in it and sometimes a trace of hexane. The volatile emission pattern varies widely in different climatic conditions and between different genotypes.

Presence of all volatile compounds in the flowers only will give good quality concrete. In nature all the volatile compounds are fixed in the flowers with fibrous materials. Concrete is extracted from the freshly harvested flower or when the fragrance emission is slow. All the fragrance compounds are not easily released from the fibrous materials of the flowers. It is advisable to do the extraction of concrete when the major fragrance compounds are started to release vigorously i.e. when sudden increase in fragrance takes place from the harvested flower.

Gas Chromatography-Mass Spectrometry (GCMS) is a process that integrated the features of gas chromatography and mass spectrometry to improve efficacy of qualitative and quantitative analysis within a test sample. The gas chromatograph applies which depend on the column (type, material, length, diameter, film thickness) as well as the phase properties. The mass spectrometer does this by breaking each molecule into ionized fragments and detecting these fragments using their mass to charge ratio (Bramer, 1998). Applications of GC-MS include drug detection, plasma detection, fire investigation, environmental analysis, explosives investigation, and identification of unknown samples. Additionally, it can identify trace elements in materials that were previously thought to have disintegrated beyond identification. The purpose of this study was to identify the volatile compounds released from three genotypes of Jasminum grandiflorum viz., $\mathrm{CO}-1$ pitchi, $\mathrm{CO}-2$ pitchi and White pitchi.

\section{Materials and Methods}

\section{Flower preparations}

Freshly opened blossoms were collected every day before 9.30 a.m., weighed and subjected to extraction.

\section{Extraction method- Solvent extraction}

For extraction of concrete, the flowers were harvested when fully opened before 9.30 AM. Concrete content of flowers was analyzed by solvent extraction method (ASTA, 1960) with food grade hexane, averaged and expressed in per cent of concrete recovery. A sample of fifty gram was taken in the glass column of Soxhlet appraratus and concrete content was estimated using food grade hexane as solvent. Soluble extract was then drained off into a pre weighed $100 \mathrm{ml}$ beaker $\left(\mathrm{W}_{1}\right)$.

The extract was then evaporated on a steam bath and heated for 30 minutes in an oven at $60^{\circ} \mathrm{C}$, cooled and weighed $\left(\mathrm{W}_{2}\right)$.

The concrete content was calculated using the following formula and expressed in per cent. 
Concrete content $(\%)=\frac{\mathrm{W}_{2}-\mathrm{W}_{1}}{50} \times 100$

\section{Volatile compound analysis using GC/MS} analysis

The volatile oil from jasmine flowers was dissolved in hexane and directly injected into the injection port of gas chromatograph (Agilent Technologies 7890A GC system) coupled with a mass spectrometer (Agilent Technologies 5975C inert XL EI/CI MSD with Triple-Axis Detector).The GC was operated on an Agilent J\&W GC column HP5 column $(30 \mathrm{~m} \times 0.32 \mathrm{~mm}$, id. with $0.52 \mu \mathrm{m}$ film thickness) and helium was used as the carrier gas.

The temperature program was started with an initial temperature of $150^{\circ} \mathrm{C}$ and held for 4 min at this temperature, then heated up to $170^{\circ} \mathrm{C}$ with a heating rate of $0.8^{\circ} \mathrm{C} / \mathrm{min}$ and held for $1 \mathrm{~min}$, heated up to $220^{\circ} \mathrm{C}$ with a heating rate of $3.0^{\circ} \mathrm{C} / \mathrm{min}$ and held for $1 \mathrm{~min}$, heated up to $240^{\circ} \mathrm{C}$ with a heating rate of $1.0^{\circ} \mathrm{C} / \mathrm{min}$ and held for $1 \mathrm{~min}$ and heated up to $250^{\circ} \mathrm{C}$ with a heating rate of $5.0^{\circ} \mathrm{C} / \mathrm{min}$ and held for $5 \mathrm{~min}$ at a flow rate of $0.7 \mathrm{~mL} / \mathrm{min}$. The obtained mass spectra were preliminarily interpreted by comparing with those of Enhance Chemstation Version D00.00.38 (Agilent Technologies), the Mass Spectral
Search Library of the National Institute of Standards and Technology (NIST, Gaithersburg, USA).

\section{Results and Discussion}

The concrete of three genotypes of Jasminum grandiflorum viz., CO-1 pitchi, CO-2 pitchi and White pitchi was prepared by solvent extraction. The percentage of the concrete in jasmine genotypes was ranged from 0.29 to $0.34 \%$ per cent (Table 1). The highest recovery of 0.34 per cent was observed in White pitchi while the genotype CO-1 recorded 0.29 percent and CO-2 recorded 0.32 percent. The chromatogram generated by gas chromatography shows the composition of the volatile oils from Jasminum grandiflorum genotypes viz., CO-1 pitchi, CO-2 pitchi and White pitchi (Fig.1).

GC/MS analysis of CO-1 pitchi concrete resulted in the identification of major compounds as Pentane,3-ethyl-2,2,2dimethyl-; Pentane-2,2,3,4-tetramethyl-; 1Pentanol,4-methyl-2-propyl-; Isobutyl vinylacetate; 2-Butanamine,3,3-dimethylfound as major compounds (Table 2, Fig 2). Whereas, 1-Heptatriacotanol; Ethyl isoallocholate; Tricyclo triacontane, 1, 7diepoxy; Cholestan-3-01, 2-methylene- and E, E, Z-1, 3, 12-Nonadecatriene-5, 14-diol were present as minor compounds.

Table.1 Concrete recovery from Jasminum grandiflorum flowers

\begin{tabular}{|c|l|c|}
\hline S.No. & \multicolumn{1}{|c|}{ Genotypes } & Concrete recovery (\%) \\
\hline 1. & CO-1 pitchi & 0.29 \\
\hline 2. & CO-2 pitchi & 0.32 \\
\hline 3. & White pitchi & 0.34 \\
\hline \multicolumn{2}{r|}{ SE(D) } & 0.03 \\
\hline \multicolumn{2}{r|}{ CD $(0.5)$} & 0.07 \\
\hline
\end{tabular}


Table.2 Chemical composition of J. grandiflorum genotype CO-1 pitchi concrete

\begin{tabular}{|l|l|l|c|c|}
\hline S.No & RT & \multicolumn{1}{|c|}{ Compounds available } & $\begin{array}{c}\text { Molecular } \\
\text { weight }\end{array}$ & $\begin{array}{c}\text { \% Retention } \\
\text { area }\end{array}$ \\
\hline 1. & 2.14 & $\begin{array}{l}\text { Pentane,3-ethyl-2,2,2- } \\
\text { dimethyl- }\end{array}$ & 128 & 69.66 \\
\hline 2. & 2.14 & Pentane-2,2,3,4-tetramethyl- & 128 & 69.66 \\
\hline 3. & 2.14 & $\begin{array}{l}\text { 1-Pentanol,4-methyl-2- } \\
\text { propyl }\end{array}$ & 144 & 69.66 \\
\hline 4. & 2.14 & Isobutyl vinylacetate & 142 & 69.66 \\
\hline 5. & 2.14 & 2-Butanamine,3,3-dimethyl- & 101 & 69.66 \\
\hline 6. & 32.46 & Tetracosane & 338 & 7.91 \\
\hline 7. & 32.46 & Tetratriacontane & 478 & 7.91 \\
\hline 8. & 32.46 & Octacosane & 394 & 7.91 \\
\hline 9. & 32.46 & Nonacosane & 408 & 7.91 \\
\hline 10. & 32.46 & Triacontane & 422 & 7.91 \\
\hline
\end{tabular}

Table.3 Chemical composition of J. grandiflorum genotype CO-2 pitchi concrete

\begin{tabular}{|l|l|l|c|c|}
\hline S.No & RT & Compounds available & $\begin{array}{c}\text { Molecular } \\
\text { weight }\end{array}$ & $\begin{array}{c}\text { \% Retention } \\
\text { area }\end{array}$ \\
\hline 1. & 2.17 & 1-Pentanol, 4-methyl-2-propyl- & 144 & 34.49 \\
\hline 2. & 2.17 & 1-Hexene,3,4-dimethyl- & 112 & 34.49 \\
\hline 3. & 2.17 & 1-Hexene,3,5-dimethyl- & 112 & 34.49 \\
\hline 4. & 2.17 & 2-Undecene,10-methyl- & 168 & 34.49 \\
\hline 5. & 2.17 & 1-Decene,9-methyl & 154 & 34.49 \\
\hline 6. & 35.79 & Tetratriacontane & 478 & 12.11 \\
\hline 7. & 35.79 & Tetracosane & 338 & 12.11 \\
\hline 8. & 35.79 & Triacontane & 422 & 12.11 \\
\hline 9. & 35.79 & Nonacosane & 408 & 12.11 \\
\hline 10. & 35.79 & Heptacosane & 380 & 12.11 \\
\hline
\end{tabular}


Table.4 Chemical composition of J. grandiflorum genotype White pitchi concrete

\begin{tabular}{|l|l|l|c|c|}
\hline S.No & RT & Compounds available & Molecular weight & \% Retention area \\
\hline 1. & 2.17 & 1-Pentanol, 4-methyl-2-propyl- & 144 & 37.30 \\
\hline 2. & 2.17 & 1-Hexene,3,4-dimethyl- & 112 & 37.30 \\
\hline 3. & 2.17 & 2-Undecene,10-methyl- & 168 & 37.30 \\
\hline 4. & 2.17 & 1-Decene,9-methyl & 154 & 37.30 \\
\hline 5. & 2.17 & 1-Hexene,3,5-dimethyl- & 112 & 37.30 \\
\hline 6. & 32.96 & Tetratriacontane & 478 & 9.63 \\
\hline 7. & 32.96 & Tetracosane & 338 & 9.63 \\
\hline 8. & 32.96 & Octacosane & 394 & 9.63 \\
\hline 9. & 32.96 & Triacontane & 422 & 9.63 \\
\hline 10. & 32.96 & Nonacosane & 408 & 9.63 \\
\hline
\end{tabular}

Fig.1 The GC chromatograms of volatile compounds of Jasminum grandiflorum flowers (CO-1 pitchi, CO-2 pitchi and White pitchi)
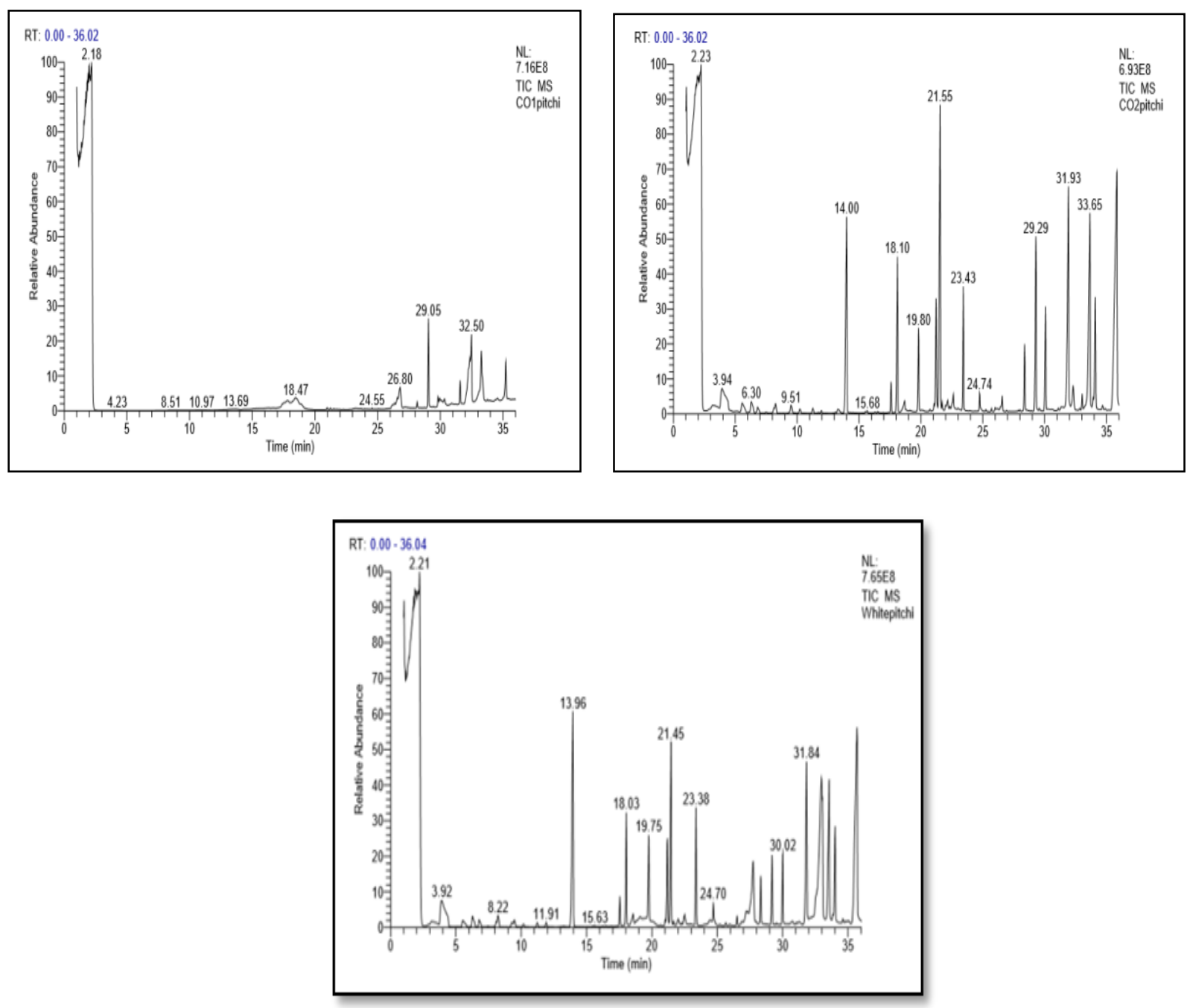
Fig.2 Chemical structure of volatile compounds of Jasminum grandiflorum genotype CO-1 pitchi
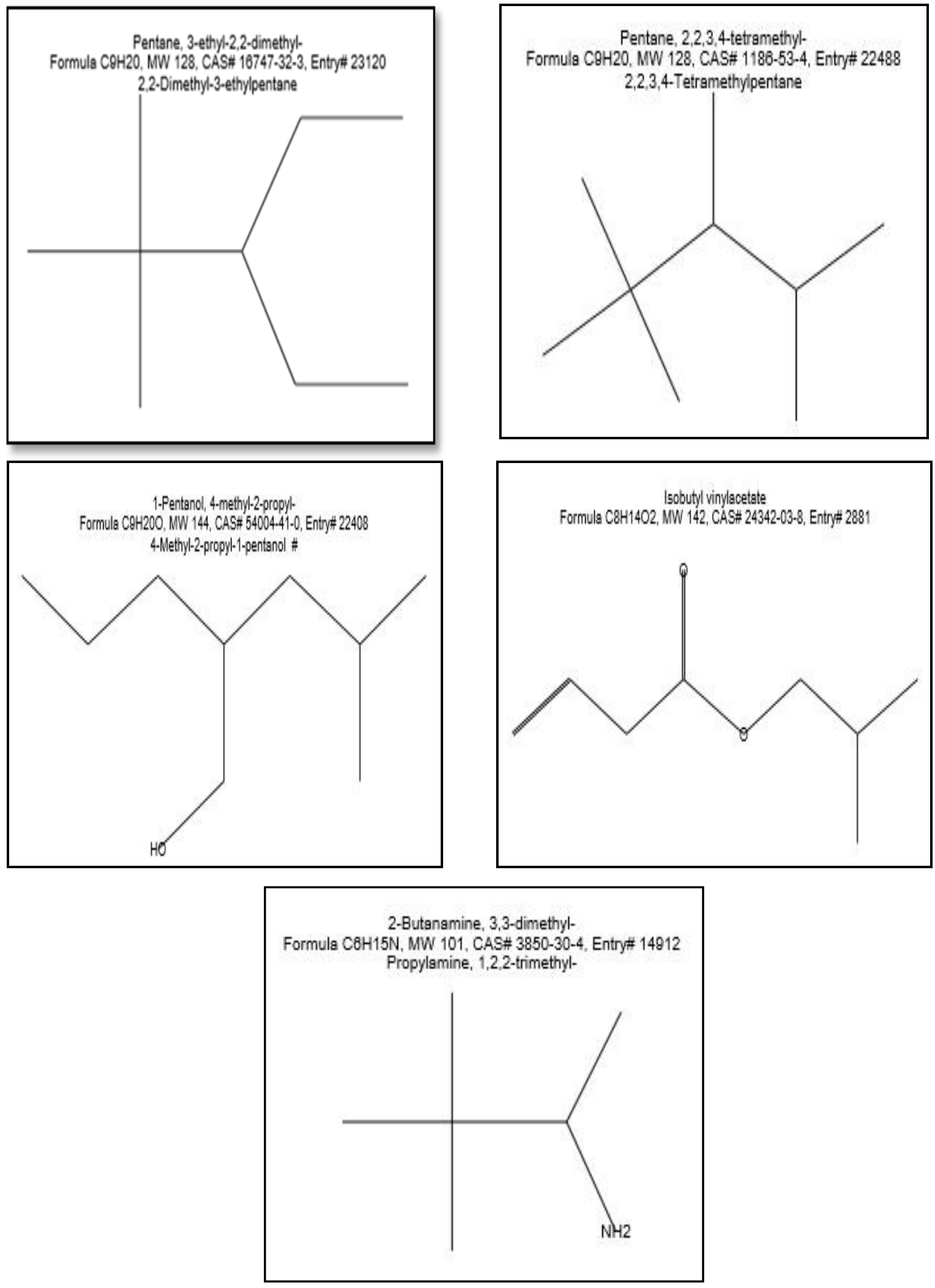
Fig.3 Chemical structure of volatile compounds of Jasminum grandiflorum genotype CO-2 pitchi
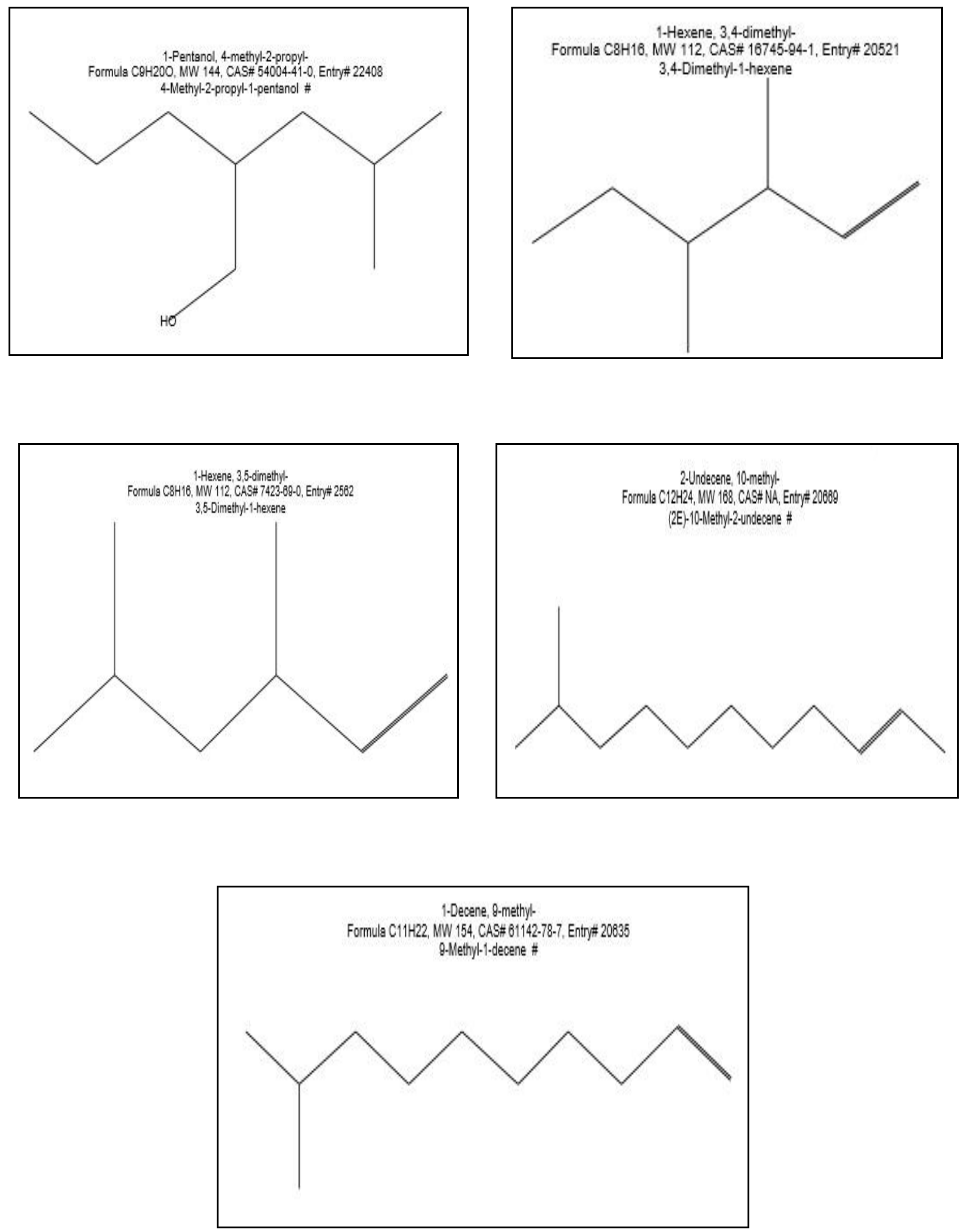
Fig.4 Chemical structure of volatile compounds of Jasminum grandiflorum genotype White pitchi
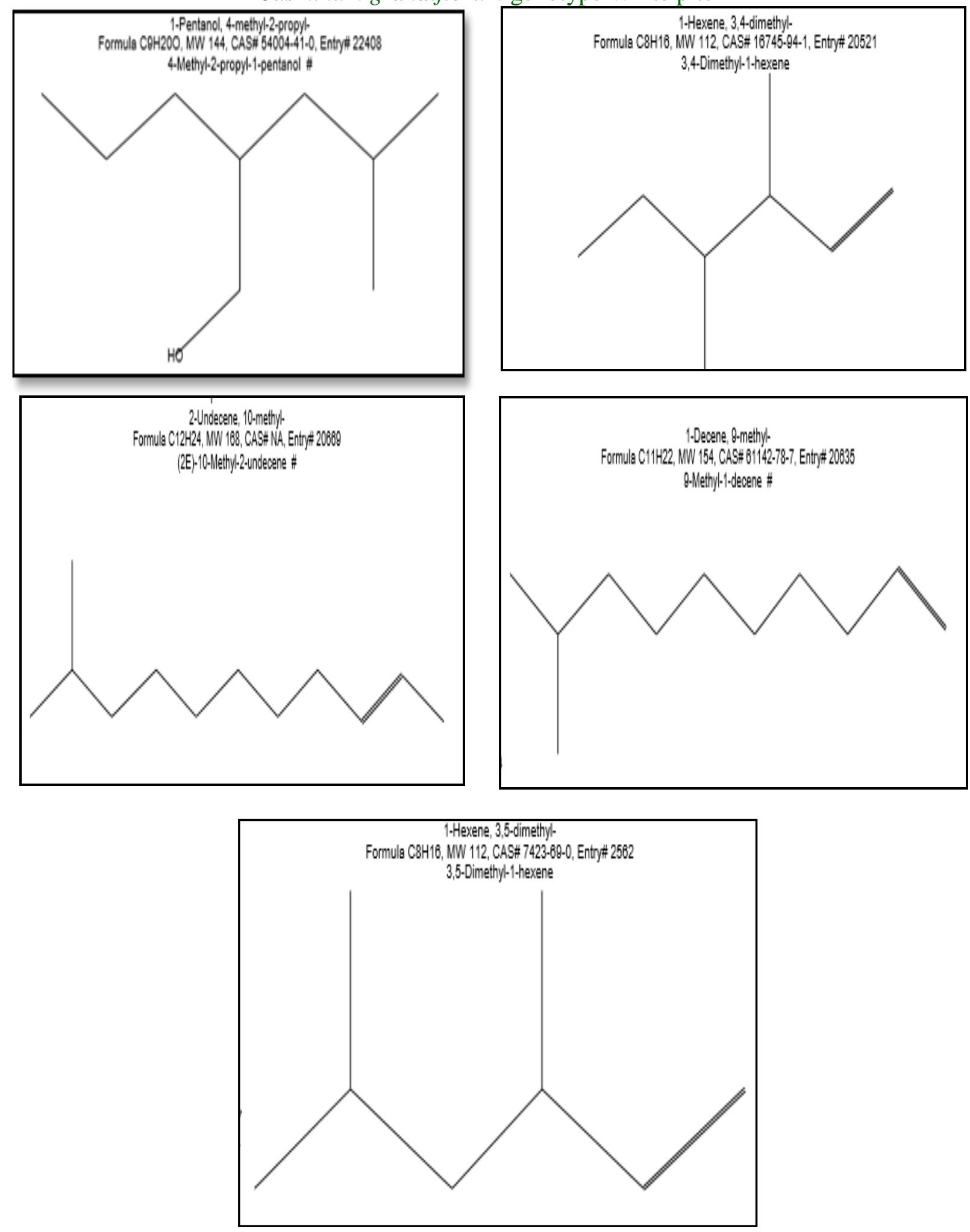
In CO-2 pitchi concrete, 1- Pentanol, 4methyl-2-propyl-; 1-Hexene, 3, 4-dimethyl-; 1-Hexene, 3, 5-dimethyl-; 2-Undecene, 10methyl-; 1-Decene, 9-methyl were contributed as major constitutes (Table 3 and Fig 3). While, Spiro(4.5)decan-7-one; 1,8-dimethyl8,9-epoxy-4-isopropyl-; 2-Methyl-E, E-3, 13octadecadien-1-ol; 3, 9-Dimethyltricyclo [4.2.1.1.(2,5)] decan-9-ol; 1-Heptadec-1-ynylcyclohexanol; Cinnamic acid, 4-hydroxy,3methoxy, ester were present as minors or traces.

In White pitchi concrete, 1-Pentanol, 4methyl-2-propyl-; 1-Hexene,3,4-dimethyl-; 2Undecene, 10-methyl-; 1-Decene,9-methyl and 1-Hexene,3,5-dimethyl were expressed as major compounds (Table 4, Fig 4). Whereas, 5-Hexadecenoic acid,2-methoxy-, methyl ester; 2,5-Octadecadiynoic acid, methyl ester; 5,9-Dimethyl-1-(3-phenyl-oxiran-2-yl)-deca4,8-dienylidene; Androstan-17-one,3-ethyl-3hydroxy-; Doconexent were present as minors or traces.

\section{References}

ASTA 1960. Official analytical methods of the American Spice Trade Association, New York, pp. 41-42.

Bramer S. E. V.1998. An Introduction to Mass Spectrometry. Widener University. Department of Chemistry. pp.26.

Green, P. and Miller, D. 2009. The genus Jasminum in cultivation. Kew Publishing, Royal Botanic Gardens, Kew.

Kulkarmi, P.H. and Ansari, S. 2004. The Ayurvedic Plants. Indian Medical Science, 132:9.

Rimando, T. J. 2003. Sampaguita production. In: Ornamental Horticulture: A little giant in the tropics. SEAMEO SEARCA and UPLB, College, Los Banos, Laguna, Philippines, pp: 333.

Sharma, P.C., Yelne, M.B. And Dennis, T.J. 2005. Data base on Medicinal Plants Used in Ayurveda. CCRAS, New Delhi, 332-345.

\section{How to cite this article:}

Ranchana, P., Ganga, M., Jawaharlal, M. and Kannan, M. 2017. Characterization of Volatile Compounds from the Concrete of Jasminum grandiflorum Flowers. Int.J.Curr.Microbiol.App.Sci. 6(7): 1883-1891. doi: https://doi.org/10.20546/ijcmas.2017.607.225 